\title{
Evaluation of some physicochemical properties as quality control parameters of an ayurvedic preparation "Khadirarishta"
}

\author{
Kamrun Nahar ${ }^{1}$, Most. Shammi Rahman ${ }^{1}$, Shahana Jahan ${ }^{1}$, Md. Zakir Sultan ${ }^{2}$, \\ Md. Musfaqur Rahman Sajjad ${ }^{3}$, Md. Taimuzzaman Sharif ${ }^{3}$, Nur Jaharat Lubna ${ }^{4}$, \\ Abu Asad Chowdhury ${ }^{3}$, Shaila Kabir ${ }^{3}$, Mohammad Shah Amran ${ }^{3, *}$ \\ ${ }^{1}$ Department of Pharmacy, State University of Bangladesh, Dhanmondhi, Dhaka, Bangladesh \\ ${ }^{2}$ Centre for Advanced Research in Sciences, University of Dhaka, Dhaka-1000, Bangladesh \\ ${ }^{3}$ Department of Pharmaceutical Chemistry, Faculty of Pharmacy, University of Dhaka, Dhaka-1000, Bangladesh \\ ${ }^{4}$ Department of Pharmacy, Primeasia University, Banani, Dhaka, Bangladesh
}

\section{Email address:}

amranms@du.ac.bd (M. S. Amran)

\section{To cite this article:}

Kamrun Nahar, Most. Shammi Rahman, Shahana Jahan, Md. Zakir Sultan, Md. Musfaqur Rahman Sajjad, Md. Taimuzzaman Sharif, Nur Jaharat Lubna, Abu Asad Chowdhury, Shaila Kabir, Mohammad Shah Amran. Evaluation of Some Physicochemical Properties as Quality Control Parameters of an Ayurvedic Preparation "Khadirarishta". European Journal of Preventive Medicine. Vol. 3, No. 2, 2015 , pp. 17-21. doi: $10.11648 /$ j.ejpm.20150302.11

\begin{abstract}
Traditional or alternative medicines such as Ayurvedic drugs are getting importance and reputation day by day in the treatment of various diseases. This is because it has fewer side effects and gives necessary pharmacological action. But prolonged and excess usage may lead to harmful effects such as damage of the heart muscle leading to various types of arrhythmia and coronary artery diseases. "Khadirarista", an Ayurvedic drug, was traditionally used for heart diseases along with jaundice, anemia, abdominal tumor and leprosy. The physicochemical properties such as pH, density, viscosity, conductivity, loss on drying (LOD), chromatographic and spectral study, and presence of metal ions the drug "Khadirarista" were studied. It was found that $\mathrm{pH}$ values were $4.53,4.21$ and 4.31 at $1 \%, 5 \%$ and $10 \%$ of test solution, respectively. It indicated that "Khadirarishta" was an acidic preparation. Density, average viscosity and residue (LOD) of the drug was 1.0076 $\mathrm{g} / \mathrm{mL}, 25.22 \mathrm{pascal} / \mathrm{second}$ and $9.33 \mathrm{~g} / 100 \mathrm{~mL}$, respectively. The spectral study of the test sample was performed and peaks were obtained at the wavelengths of $275,254,274.80,254.60,275.60,273.60,211,253.60 \mathrm{~nm}$ in UV spectrophotometer with $276.60 \mathrm{~nm}$ being the $\lambda_{\max }$. HPLC analysis of the sample was performed and retention time $\left(\mathrm{R}_{\mathrm{t}}\right)$ of the possible active components were found to be $4.12,4.22$ and $4.83 \mathrm{~min}$. $\mathrm{R}_{\mathrm{t}}$ at $4.12 \mathrm{~min}$ was the most sharp peak. Applying TLC, the $\mathrm{R}_{\mathrm{f}}$ values of the active compounds were found to be 0.6 and 0.7 . The level of various metal ions in the sample was measured by Flame Photometry and $\mathrm{Na}$, K, Ca levels were found to be 75 ppm, 5 ppm, 12 ppm, respectively.
\end{abstract}

Keywords: Khadirarishta, HPLC, Flame Photometry, Physicochemical Parameters

\section{Introduction}

Plant and man are, were and will be inseparable, because plants not only provide us with food, shelter and medicine but also the life sustaining oxygen gas. Since, disease, decay and death have always co-existed with human civilization; the early man had to think about disease and its treatment at the dawn of intellect. Thus the race started using plants as a means of treatment of diseases and injuries. Human race has successfully used plants and products thereof as effective therapeutic tools for fighting against disease and various health hazards ${ }^{1}$. Medicinal plants are the principal healthcare resources for the majority of people all over the world. Pharmaceutical importance of plants has led to the discovery and adoption of plant extracts which were commonly used in traditional medicine as alternative source of remedy ${ }^{2}$. Herbal medicines refer to the use of any plant seed, berries, roots, leaves, bark or flower for medicinal purpose ${ }^{3}$. The economic significance of medicinal plants stems from the fact that the number of patients suffering from chronic ailments is on the rise and drugs from medicinal plants are proving to be more 
effective in treating such disorders ${ }^{4,5,6}$. Medicinal and aromatic plants (MAPs) are produced and offered in a wide variety of products, from crude materials to processed and packaged products like pharmaceuticals, herbal remedies, teas, spirits, cosmetics, sweets, dietary supplements, varnishes and insecticides ${ }^{7-9}$. Ayurvedic medicine is still the mainstay of the world's populations for primary health care because of better cultural acceptability, better compatibility with the human body and few side effects. Now a day's many Ayurvedic preparation are used for the different disease purpose, but have not proven scientific evidence about their proper action and lethal dose.

Ayurveda is used to restore the physical, mental and emotional balance in patients, thereby improving health, preventing disease and also treating any current illness ${ }^{11}$. It is a Sanskrit term, made up of the words "ayus" and "veda". "Ayus" means life and "Veda" means knowledge or science. The term "Ayurveda" thus means 'the knowledge of life' or 'the science of life ${ }^{\prime 2}$. The quality control of herbal drugs is repeatedly asked question that bewildered the scientist community. Strict quality control of traditional medicine is based largely on the empirical measurement of few nonspecific physical properties such as $\mathrm{pH}$, viscosity, density etc. But quality control by specific methods still faces authenticity. This problem lies in the process of manufacture of the traditional drugs. However, we have taken this research work to evaluate the quality control parameters of marketed preparation "Khadirarishta". 'Khadirarishta" is an Ayurvedic preparation and manufactured by Sree Kundeswari Aushadhalaya Ltd., Chittagong, Bangladesh as liquid by arista process. ${ }^{16}$

\section{Methods and Materials}

\subsection{Study of Physical Properties of Khadirarishta}

\subsubsection{Determination of $\mathrm{pH}$}

The $\mathrm{pH}$ of the drug was determined at $1 \%$ solution, $5 \%$ solution and $10 \%$ solution by using $\mathrm{pH}$ meter $(\mathrm{pH}-211$ Microprocessor, HANNA, Japan).

\subsubsection{Determination of Conductivity}

The conductivity of the drug was determined at $1 \%$ solution, $5 \%$ solution and $10 \%$ solution by using conductivity meter (EC-215 Conductivity Meter, HANNA, Japan).

\subsubsection{Determination of Density}

The density, $\rho$, is elementary physical property of matter. For a homogeneous object, it is defined as the ratio of its mass $\mathrm{m}$ to its volume $\mathrm{V}$.

$$
\rho=m / V
$$

Density was determined by pycnometer. The weight of blank pycnometer was taken and then filled the pycnometer with distilled water and weighed it again. After then pycnometer was filled with Khadirarishta and weighed. Then weight of Khadirarishta with pycnometer minus blank pycnometer divided by volume of pycnometer ${ }^{17}$.
Density $=[($ Weight of pycnometer with test sample - weight of blank pycnometer)/Volume of liquid in pycnometer]...(ii)

\subsubsection{Determination of Viscosity}

The viscosity of $1 \%, 5 \%$ and $10 \%$ drug solutions was determined by using Viscosity tube. At first used $1 \%$ solution which was kept in viscosity tube up to the mark and start to time count. When the solution reached the finish mark then it was stopped. It was done for $5 \%$ and $10 \%$ solution in the same way.

\subsubsection{Determination of Loss on Drying}

At first $100 \mathrm{~mL}$ Khadirarishta was taken in a beaker and was weighed. Then Khadirarishta with beaker was put in a water bath for completing evaporation. The residue was weighed after cooling.

LOD $=$ Weight test sample before evaporation - weight test sample after evaporation.

\subsection{UV Spectral Study}

\subsubsection{Apparatus}

UV-Visible Spectroscopy: A PC based UV-Visible recording spectrometer-1700 Series (Shimadzu, Japan), with slit width $1.0 \mathrm{~nm}$, light source change wavelength at 340.8 $\mathrm{nm}$ was employed for all measurements.

\subsubsection{Preparation of Test Sample}

For UV study $0.1 \%, \quad 0.25 \%, \quad 0.5 \%$ solutions of Khadirarishta were prepared and the solutions were scanned at $200-800 \mathrm{~nm}$.

\subsection{Thin Layer Chromatographic Analysis}

Khadirarishta comprises active and inactive compounds, therefore, to identify these compounds thin layer chromatographic (TLC) technique was used with chloroform and ethyl acetate at different ratios as solvent systems. The following characteristics (Table 1) were used to determine the number of compounds present in the Khadirarishta.

Table 1. Characteristics of TLC plate.

\begin{tabular}{ll}
\hline Item & Characteristics \\
\hline Plate size & $8 \mathrm{~cm} \times 3 \mathrm{~cm}$ \\
Stationary phase & Thin film of silica gel GF \\
Film thickness & $0.5 \mathrm{~mm}$ \\
Activation & at $110^{\circ} \mathrm{C}$ for one hour \\
Type of development & Ascending and one-dimensional \\
\hline
\end{tabular}

\subsubsection{Detection of Compound by $R_{f}$ Value}

There was no specific reagent for easily detection of antimicrobial compound(s). Therefore, simple method like spraying with a characteristic reagent on the TLC plate could be used to detect antibiotics. However, following processes (Table 2) were utilized in order to ascertain the number of compounds present in Khadirarishta. 
Table 2. Processes for of TLC plate.

\begin{tabular}{ll}
\hline Item & Processes \\
\hline \multirow{3}{*}{ i) UV light } & $\begin{array}{l}\text { The developed and dried TLC plates were } \\
\text { visualized under UV light }(254 \mathrm{~nm}) \text { to locate } \\
\text { UV absorbing or quenching compounds. } \\
\text { The plate sprayed with } 1 \%(\mathrm{~W} / \mathrm{V}) \text { vanillin in } \\
\mathrm{H}_{2} \mathrm{SO}_{4} \text { reagent and then heated at } 110^{\circ} \mathrm{C} \text { for } \\
\text { ii) Vanillin-sulfuric } \\
\text { acid spray reagent } \\
\begin{array}{l}10-15 \text { minutes. The resolved compounds were } \\
\text { detected with the development of a specific } \\
\text { color }\end{array}\end{array}$ \\
\hline
\end{tabular}

\subsection{Study by Using HPLC}

\subsubsection{Column}

Analytical reversed phase C-18 column [Luna C-18, $5 \mu$. $250 \times 4.6 \mathrm{~mm}$, Phenomenex, Inc] was used to analyze the samples.

\subsubsection{Mobile Phase}

Nano pure water was sonicated for $10 \mathrm{~min}$ and then it was filtered through a $0.22 \mu \mathrm{m}$ Millipore filter and degassed. HPLC grade $50 \%$ methanol and 50\% water were sonicated and filtered through $0.22 \mu \mathrm{m}$ Millipore filter and degassed before using.

\subsubsection{Chromatographic Conditions}

All analysis was done at ambient temperature under isocratic condition. The mobile phase comprised of $50 \%$ aqueous methanol at the flow rate $0.7 \mathrm{~mL} / \mathrm{min}$. The injection volume was $20 \mu \mathrm{L}$. Before analysis, every sample was filtered through $0.45 \mu \mathrm{m}$ filter tips. The column eluate was monitored with UV detection at $254 \mathrm{~nm}$.

\subsubsection{Preparation of Test Sample}

$1 \mathrm{~mL}$ drug were weighted and dissolved in $9 \mathrm{~mL}$ water and then sonicated for $10 \mathrm{~min}$ and then filtered through $0.45 \mu \mathrm{m}$ filter tips and filled the sample in vial.

\subsection{Detection of Metal (Sodium, Potassium, Calcium)}

To prepare standard solution of sodium, potassium, calcium solution the concentration was $60 \mathrm{ppm}, 50 \mathrm{ppm}, 40$ ppm, 30 ppm, 20 ppm were selected.

\subsubsection{Preparation of Test Sample}

To prepare the test sample $5 \mathrm{~mL}$ of Khadirarishta in $50 \mathrm{~mL}$ volumetric flask was collected and made up to $50 \mathrm{~mL}$ for sodium and calcium ion analysis. In this experiment potassium ion was to be large and for that 500 times dilution of Khadirarishta was used for determination of potassium ion.

\section{Results and Discussion}

\subsection{Physiochemical Parameters}

Physicochemical tests of Khadirarishta was performed to measured the physicochemical parameters and it was found that $\mathrm{pH}$ of the solution was $4.53,4.21,4.31$ for $1 \%, 5 \%$ and 10 solutions of test drug which indicated that Khadirarishta is an acidic preparation. Density of drug was found to be as
$1.0076 \mathrm{~g} / \mathrm{mL}$, the average viscosity was $25.22 \mathrm{pascal} / \mathrm{second}$ and the residue (LOD) of Khadirarishta was $9.33 \mathrm{~g} / 100 \mathrm{~mL}$. The conductivity test was also carried out and results were shown in the Table 1.

In the experiment of viscosity determination of Khadirarishta in viscosity tube, the viscosity of time was 25.59 pascle/second, 25.14 pascle/second, 24.89 pascle/second and average time was 25.22 pascle/second.

Table 3. Conductivity determination in different solutions.

\begin{tabular}{lll}
\hline $\begin{array}{l}\text { Percent of } \\
\text { Solution }\end{array}$ & $\begin{array}{l}\text { Conductivity }(\text { scale } \\
=\mathbf{1 9 . 9 9} \mathbf{~ m s})\end{array}$ & $\begin{array}{l}\text { Conductivity }(\text { scale }=\mathbf{1 9 9 9} \\
\boldsymbol{\mu s})\end{array}$ \\
\hline $1 \%$ & 0.15 & 164 \\
$5 \%$ & 0.52 & 520 \\
$10 \%$ & 0.97 & 961 \\
\hline
\end{tabular}

\subsection{UV Spectral Study}

The UV Spectrum of Khadirarishta contained various compounds which were detected by UV spectrophotometer as shown in Table 4 and Figure 1.

Table 4. Absorptive values

\begin{tabular}{lll}
\hline $\begin{array}{l}\text { Concentration } \\
\text { (Percent of Solution) }\end{array}$ & Wavelength & Absorbance \\
\hline \multirow{2}{*}{0.1} & 275.00 & 0.156 \\
& 254.20 & 0.139 \\
0.25 & 274.80 & 0.362 \\
& 254.60 & 0.316 \\
& 275.60 & 0.667 \\
0.5 & 273.60 & 0.667 \\
& 211.00 & 2.637 \\
& 253.60 & 0.579 \\
& 210.20 & 2.572 \\
\hline
\end{tabular}

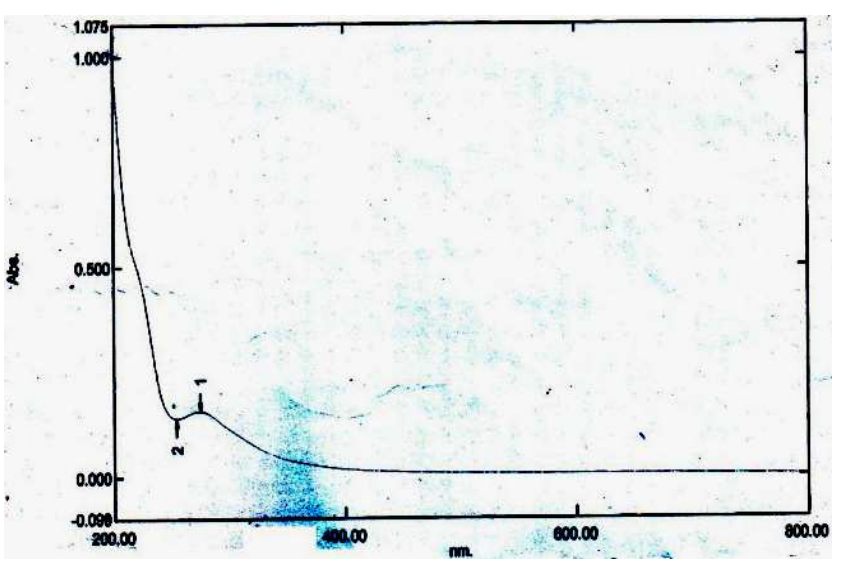

A 

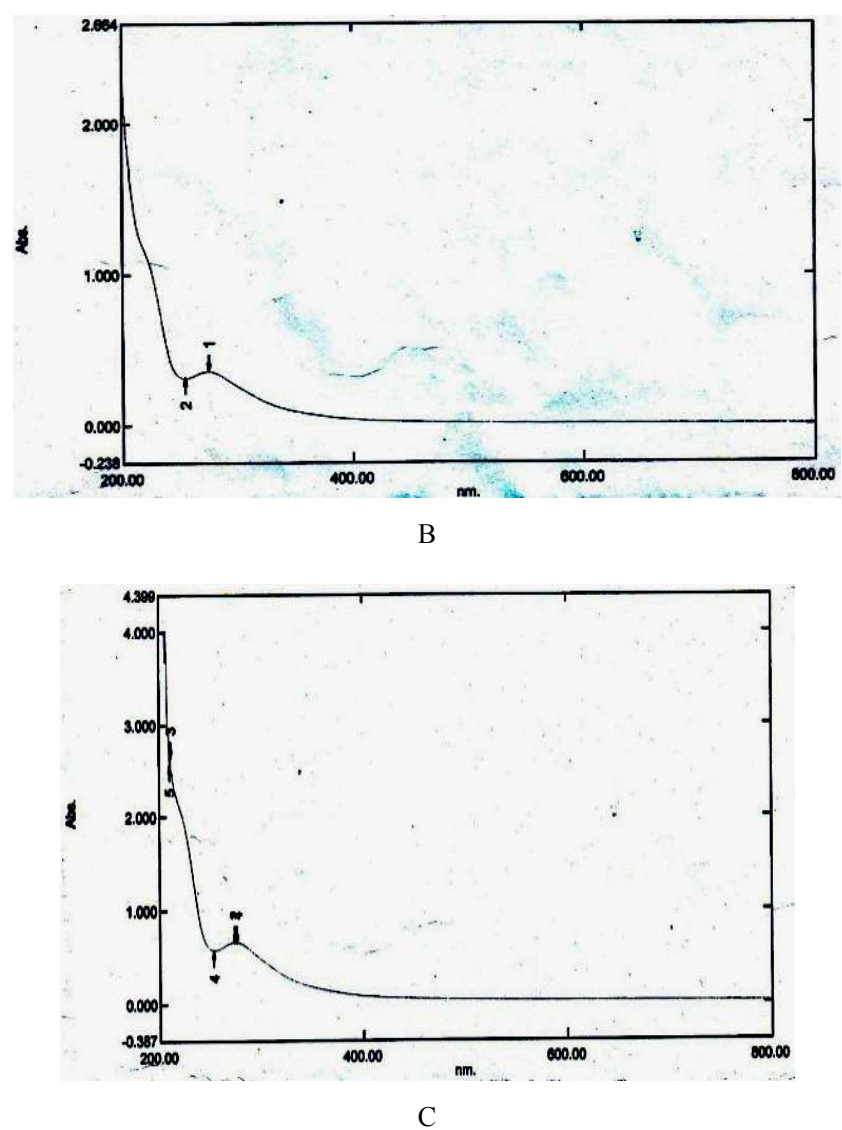

Figure 1. UV spectra of Khadirarishta $(A=0.1 \%$ solution, $B=0.25 \%$ solution, $C=0.5 \%$ solution)

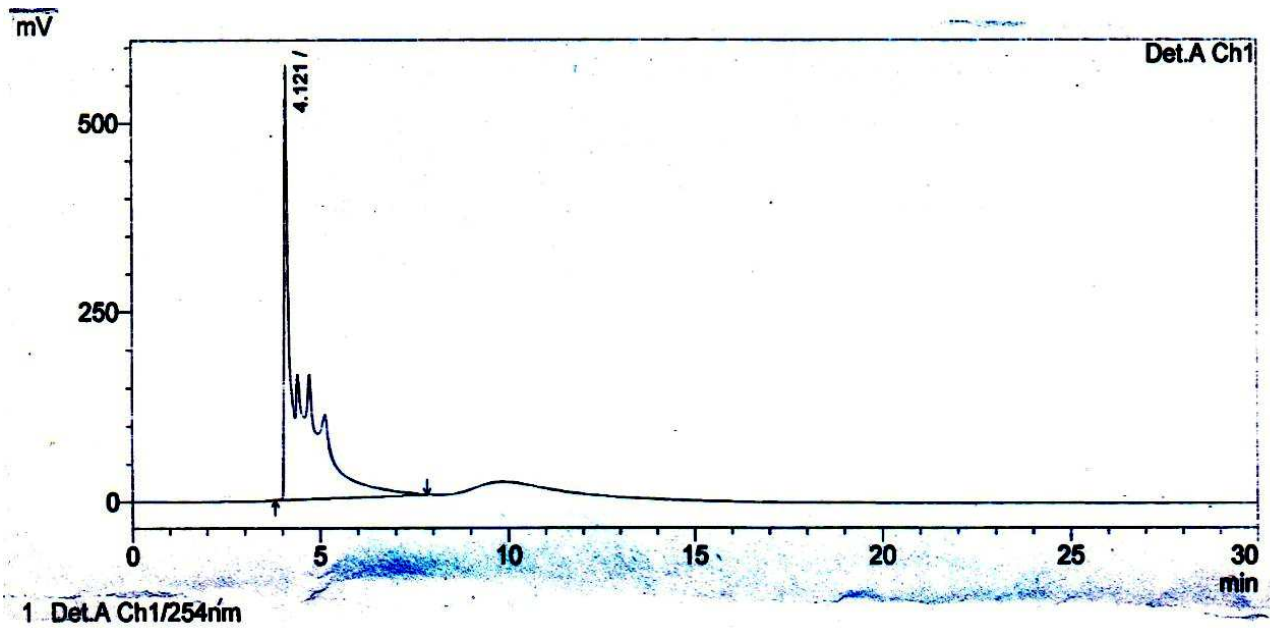

Figure 2. HPLC analysis of khadirarishta

\subsection{Determination of Metal}

In the detection of metal analysis we found too much sodium present in Khadirarishta with minimum amount of calcium. $\mathrm{Na}, \mathrm{K}, \mathrm{Ca}$ levels were found to be $75 \mathrm{ppm}, 5 \mathrm{ppm}$, $12 \mathrm{ppm}$.

\section{Conclusion}

The preparations from different batches showed similar results.

\subsection{TLC Study}

Table 5. Results of TLC analysis (Observation under UV light and after spraying).

\begin{tabular}{llll}
\hline Compounds & $\begin{array}{l}\text { Observation under } \\
\text { UV light }\end{array}$ & $\mathbf{R}_{\mathbf{f}}$ value & $\begin{array}{l}\text { Observation } \\
\text { after Spraying }\end{array}$ \\
\hline Compound-1 & $\begin{array}{l}\text { Glowing deep } \\
\text { (254nm) pink }\end{array}$ & 0.6 & ---------- \\
Compound-2 & $\begin{array}{l}\text { Glowing deep } \\
\text { (254nm) violet }\end{array}$ & 0.7 & $\begin{array}{l}\text { Glowing deep } \\
\text { pink }\end{array}$ \\
\hline
\end{tabular}

To determine the $\mathrm{R}_{\mathrm{f}}$ values of the Khadirarishta compounds a spot for each of compounds were given on a TLC plate and it was run using Chloroform : Ethyl acetate (EtoAC : $\mathrm{CHCl}_{3}$ ) solvent systems. The spot was found after observation under UV light and after spray of Vanillinsulfuric acid spray reagent on the TLC plate. Many compounds were found on this plate which were overlapping to each other. But one was compound in spraying method and two compounds were found in UV light clearly observed which were of the $R_{f}$ values as 0.6 and 0.7 visualized under UV light and $\mathrm{R}_{\mathrm{f}} 0.7$ after spraying (Table 5).

\subsection{HPLC Study}

HPLC chromatograms at $254 \mathrm{~nm}$ showed that Khadirarishta contained various compounds HPLC various compounds having retention time $\left(\mathrm{R}_{\mathrm{t}}\right)$ at $4.12,4.22$, and 4.83 minute (Figure 2). 
Islam, Institute of Food and Nutrition Science, University of Dhaka, Bangladesh for his kind permission to use their animal house.

(2) This work was supported by a research grant from The World Academy of Sciences (TWAS), Italy. Reference No.: 12-172 RG/BIO/AS_G; UNESCO FR;12-172 RG/BIO/AS_G.

\section{References}

[1] Ghani A (1998). Text Book of Pharmacognosy 2(1): 240.

[2] Suresh Kumar, Rohit Kumar and Altaf Khan (2011). Medicinal Plant Resources: Manifestation and Prospects of Life-Sustaining healthcare. Continental J. Biological Sciences 4 (1): $19-29$.

[3] Baquar, S.R (2001). Textbook of Economic Botany. Ferozsons (Pvt.) Ltd. Lahore: 1.

[4] Deshpande, R.S., Neelakanta, N.T. \& Hegde, N (2006). Cultivation of Medicinal Crops \& Aromatic Crops as a Mean of Diversification in Agriculture: eIX/ADRT/115.

[5] Girach R.D., Khan, H. \& Ahmad, M (2003). Botanical identification of Thuhar seldom used as unani medicine. Hamdard Medicus. XLVI (1): 27-33.

[6] Hoareau, L. \& DaSilva, E. J (1999). Medicinal plants: a reemerging health aid. Electronic Journal of Biotechnology 2 (2): 56-70.

[7] Ohrmann, R (1991). Pflanzenextrakte in Haushaltsprodukten. Dragoco Report (Holzminden) 3: 67-76.

[8] Gorecki, P (2002). Vitafoods und Kosmetika: Arzneipflanzen erobern sich neue Wirkungsbereiche. Drogenreport 28: .9-15.

[9] Lange, D (1996). Untersuchungen zum Heilpflanzenhandel in Deutschland. ein Beitrag zum internationalen Artenschutz. Bundesamt für Naturschutz, Bonn-Bad Godesberg.

[10] Courson WA (2008). State licensure and Ayurvedic practice: planning for the future, managing the present. Newsletter of the National Ayurvedic Medical Association [online journal]

[11] Mazumder Papiya Mitra ; Das Saumya ; Das Sanjita ; Das Manas Kumar (2011). Phyto-Pharmacology of Berberis aristata DC. A Review Journal of Drug Delivery \& Therapeutics 1(2): 46-50.

[12] Lakshmi.T, Anitha Roy, Geetha R.V (2011). Acacia Catechu Willd -A Gift From Ayurveda To Mankind -A Review The Pharma Research (T. Ph. Res.) 5(2): 273-293.

[13] Chopra A and Doiphode VV(2002). Ayurvedic medicinecore concept, therapeutic principles, and current relevance. Medical Clinics of North America 86(1): 75-88.

[14] Dodds JA. Know your CAM provider (2008). Bulletin of the American Academy of Orthopaedic Surgeons/American Association of Orthopaedic Surgeons [online journal].
[15] Gogtay NJ, Bhatt HA, and Dalvi SS (2002). The use and safety of non-allopathic Indian medicines. Drug Safety 25(14): 1005-1019.

[16] Bangladesh National Formulary of Ayurvedic Medicine (1992). (Approved by the Government of Bangladesh vide Ministry of Health and Family Welfare Memo No. Health1/Unani-2/89/ (Part-1) 116 dated 3-6-1991): 83-84.

[17] Kopecký, F (1999). Physics for Students of Pharmacy I. Bratislava, UK (in Slovak): 184.

[18] Pawar V. T, Pishawikar S. A., More H. N (2010). Spectrophotometric Estimation of Aceclofenac and Paracetamol from Tablet Dosage Form. Current Pharma Research 1(1): 26-29.

[19] Byrd, H., O'Donnel, S.E. A (2003). General Chemistry Laboratory Theme: Spectroscopic Analysis of Aspirin. Journal of Chemical Education 80: 174-176.

[20] K. Burger, Fresenius Z (1984). Anal. Chem. 318: .228 -233.

[21] S.Ravichandran (2011). Determination of Sodium content in the Marina beach water using Flame Photometry; International Journal of ChemTech Research 3(4): 1903-1905.

[22] Braunwald E (1997). Heart Disease: A Textbook of Cardiovascular Medicine. Philadelphia, W.B. Saunders Co 5: 108.

[23] Ganon, Review of Medical Physiology. A Lange medical book. 23: 490-503.

[24] Erik Sandoe, Bjarne Signure (1991). A Guide to Clinical Electrocardiology, Verlages Gmbh, 1: 1-34.

[25] Most. Shammi Rahman, Shahana Jahan, Kamrun Nahar, Nazia Islam, Danis Rahman, Ridwan Bin Rashid, Abu Asad Chowdhury, Rebecca Banoo and Mohammad Shah Amran (2013). Evaluation of Cardiovascular Activity of an Ayurvedic Product 'Mrityunjay' in Rat Model; Bangladesh Pharmaceutical Journal 16(1): 99-105.

[26] Mrunalini C Damle, Shangiresh Madhukar Patole, Laxman Venkatrao Potale, Amol Suresh Khodke (2010). A Validated HPLC Method for Analysis of Atrovastin Calcium, Ramipril and Aspirin as the Bulk Drug and in Combined Capsule Dosage Forms. International Journal of Comprehensive Pharmacy 1(1): 1-5.

[27] Md. Tauhid-Ul Islam, Md. Abdus Samad Bhuiyan, Md. Musfequr Rahman Shajjad, Md. Taimuzzaman Sharif, Md. Zakir Sultan, Asma Rahman, Md. Akter Hossain, Abu Asad Chowdhury and Mohammad Shah Amran. A Study of Prophylactic Effect Against Diabetes of Two Ayurvedic Drugs 'Jambadyarista' and 'Bohumutrantak Ras' in Normal as well as Alloxan-induced Diabetic Rats. British Journal of Pharmaceutical Research 4(16): 1945-1955, 2014.

[28] Md. Zakir Sultan and M. A. Rashid. Experimental Organic, Medicinal and Natural Product Chemistry. Published in February, 2014; Ashrafia Boighar, 36- Bangla Bazar, Dhaka1100, Bangladesh; Pages-339. 